\title{
EVOLUTION AND THE FALL
}

\author{
REV. CHARLES REED ZAHNISER \\ Pittsburg, $\mathrm{Pa}$.
}

There are few of the evangelical doctrines that have proved more troublesome to minds that move along lines of evolutionary theology than that of the fall. Evolution stands for gradual progress, prevailingly upward, and it is hard for it to find a place for such a catastrophe as is supposed to have occurred in the fall of man. Consequently many thinkers are discarding it entirely, treating the Genesis stories as mere Babylonian myths unworthy of serious consideration. Some have argued for a real historical basis for the narratives, but have contended that the fall was a fall upward, so to speak; that is, instead of its being a dire calamity that brought the thousand natural shocks that flesh is heir to, it was rather the birth of the moral consciousness, and the labor pains with which it came are to be forgotten in joy that the race was thereby brought into a larger life of wider vision and greater possible achievement.

We can all agree that such a testing as the traditional theology conceived the temptation to be, would be in itself good rather than ill; it is impossible in any other way to account for the fact that it was permitted by God. Moreover, the human mind cannot conceive of positive moral character being produced otherwise. Innocence is far inferior to righteousness; the innocent soul is the tabula rasa, but the righteous soul is the page heavily inscribed by proper decisions in the testing times of life. Positive character comes only as a result of reaction against outside influences. Duties done and temptations resisted produce uprightness; duties resisted and temptations heeded produce unrighteousness. Had man never known temptation, there is no way thinkable by which he could have come to positive moral character.

This is a very different thing, however, from admitting that the result of the original testing was good. Undoubtedly the traditional theology is in accord with the conceptions of the Biblical writers in 
contending that the greatest calamity that man has ever known was the fact that in the first great testing he failed, and thereby the whole race has received a moral bias toward evil. Indeed, there is nowhere in the Bible a scintilla of contrary evidence. The doctrine has been questioned because of alleged lack of harmony with evolutionary philosophy, and for that reason alone. The contention is that, since man is a product of evolutionary processes, he could not have had such an experience, and therefore these Genesis stories are not even pictorial presentations of great truths, nor, indeed, anything more than merest worthless legends. The ground of objection is thus seen to be entirely scientific.

In the field of science itself, however, there are some things which support a belief in a fall, and which have not been given sufficient consideration. In the first place, evolutionary theory does not necessarily demand a progress that is constantly upward; most of the parasites, for example, are the product of an evolutionary process in the opposite direction. Nor, again, does it shut us up to a belief in a progress that is always gradual, with no leaps and bounds. Professor George H. Darwin, in his presidential address to the British Association for the Advancement of Science at Cape Town, said: "Certain considerations lead me to doubt whether biologists have been correct in looking for continuous transformation of species. Judging by analogy, they should rather expect to find continuous changes occurring during a long period of time, followed by a somewhat sudden transformation."

Of more importance than either of these considerations in relation to the doctrine of the fall is a positive evidence which comes to us as a result of embryological science, and which may be stated somewhat as follows:

Embryology teaches that the individual repeats in his early life the history of his ancestors. "The prenatal child passes up through every grade of animal life, from the simplest and lowest to the highest and most complex. Over one hundred and forty useless organs appear, grow, and are done away, like leaves upon this tree of life in this miracle of child-evolution." The process is not entirely prenatal either. "After birth this candidate for humanity continues this evolution, in which he has already repeated the history of the animal 
world, by repeating the history of his own race-life from savagery to civilization." This process goes on till full manhood, we are told, and in the "gangs" of boys from twelve to sixteen, for example, are being repeated the group-forming instincts of earlier civilization.

Now, it is a fact of common experience that, when a child comes to the capability of moral choice and self-assertion, it passes through such an experience as Christian theology has taught was that of the race at the stage in its history then being repeated in the life of the child. In other words, the child passes through a fall in its own experience while repeating the history of the race. When it comes to a sense of moral obligation and is compelled to choose between self-gratification and the morally right, a child invariably, if left to itself, prefers self-gratification. If there is no check placed on its decisions by older guardians, it continually repeats the action with each case in which it is forced to make a moral choice. As a result, the same bias toward evil appears, the same consciousness of guilt or accusing conscience as has been ascribed to the race as a result of the fall. This is not to contend that the fall in the experience of the child is necessarily a single act or a clearly conscious experience. Undoubtedly the form is different in different cases, and it is immaterial to the argument whether it be thought of as a single act or as a process. Moreover, it is not to be expected that one should remember the change as a distinctly conscious experience; for it occurred before he was capable of careful introspection and self-analysis. Neither is it necessary to prove that all children become equally depraved; undoubtedly this is not the case, and there are many cases of children so superior to others that they have given rise to the contention that they were "always good." All that is essential to the validity of the argument is that which everyone will admit, namely, whereas I was once an innocent babe, I have become a guilty man. Between the two conditions somewhere there has been a fall. It is futile to object that what we have called the fall in the experience of a child is but the development of innate tendencies. It is on the presumption of such tendencies as being innate that the whole scientific theory of embryonic and post-natal development rests. It is the actual development of such innate and irresistible tendencies that constitutes the repetition of race-history which the scientist considers so significant. 
The conclusion, if the premises are true, is inevitable: If the scientific theory that the history of the race is repeated in the experience of the individual is sound, and if there is a fall in ordinary human experience, the scientific presumption is that there has been a fall in the early history of mankind. Of course, this argument cannot be taken as supporting in detail a literal interpretation of the serpent story. It does not contend that the fall was necessarily a single act, or that it occurred in the experience of only two persons. So far as this argument is concerned, the fall may have come when the race was already a multitude every one of whom chose the evil. The most that it proves is that in the early history of man, whether as an individual or as a race, he came to the capability of moral choice, and when he did so he chose self-gratification at the expense of evil rather than the good, and thereby gave to his nature an enduring bias toward the evil.

It is thus made evident that, far from science disproving the doctrine of a fall, it rather substantiates it. The essential thing for which Christian theology has contended is that man's sinfulness was not his by original endowment, but has come as a result of his own wilful choice; and this is supported by the scientific presumption as above presented. The matters of detail, such as the number and nature of the original transgressions and the number of persons involved, are things to be determined, if at all, in other ways. Science cannot be expected to throw much light on them, and, indeed, to contend for them on the part of Christian doctrine seems hardly worth while. 